\title{
THE GIFT OF UNCERTAINTY
}

\author{
How can design education bring complexity and unpredictability into a positive framework for \\ designers?
}

Kristin Støren Wigum ${ }^{1}$, Tore Gulden ${ }^{2}$

1 and 2 Oslo Metropolitan University, Department of Product Design

\begin{abstract}
This paper follows Krippendorff's recommendation "to think and do things differently." In particular, we explore the potential of his reformulation of a product as an "interface" to substitute "the meaninglessness of physical properties" [1] while exploring the "deceptive notion of THE user" as "stakeholder networks" [1]. The three stepping stones of the exploration of "What is?" [2], the journey "Where can we go?" [2], and the challenge of transitioning to "the turning point" [2] to increase flow in designing with uncertainty are examined in relation to Krippendorff's reformulations of products and users, here by cases from design education on a master's level. The students in this case have worked within a grid of a more traditional design processes, but system theory was introduced, forcing the students to evolve with the discovery of open systems and their interrelations and contradictions. The aim of this paper is to explore a design approach for progress and transition and, thus, designers' future ability to meet future uncertainty and complex challenges with both humbleness and boldness. We argue how such a change of perspective may involve the exploration of new networks, relations, and experiences that support regenerative ripple effects and sustainability to handle uncertainty.
\end{abstract}

Keywords: System-oriented design education, cybernetics, designer's framework, uncertainty, diversity, sustainability, game dynamics

\section{INTRODUCTION}

Systems are reluctant to change, and the praxis (behavior and thinking) of the people who constitute the structure is influenced by the systems. To change these systems, it is efficient to make changes at a systems level [2]. Hence, the paradigm of design research is concerned with structural change, which means designers are educated within the perspective of approaching complex situations by using structural change.

In the current article, we discuss the pain of letting go of this existing illusion of the designers' ability to predict the future and alter it through structural change. The illusion typically exists in the designers' analysis of a company confined to the products or services isolated where the uncertainties are easy to recognize and resolve. Uncertainty may appear in many scales and types, as well as layers and importance of impact. Donella Meadows [9] explains how the knowledge of how systems work really shows us how much we cannot predict and how much uncertainty we actually must be prepared to meet.

Therefore, we have oriented the discussion about the assumption that the ability to handle uncertainty on a systemic level may orient designers into a new role in society and business practice. We further discuss how this may lead to a design perspective building on systems theory and cybernetics, hence emphasizing the design of new systems or changing old systems; thus, this creates the emergence of subsystems and structures that produce new types of growth and systems goals.

\subsection{Challenging design education to be relevant for future designers}

We modeled this discussion around the following research question: How can design education play a role in future designers' development in the complexity of the uncertain? Design education is slowly bringing in systems thinking to design for complex uncertainty. However, our teaching methods and design methodology, which is rooted in the making of things, cannot meet the needs for future service 
and product designers that will operate in exceedingly complex contexts [3]. The systems goal of existing design practice, which is industrial growth, perhaps needs new measures of success.

\subsection{Our need to tame the wild produce uncertainty}

Humanity's need to gain control over nature as a way to feel secure is an anthropocentric tendency that influences the epistemology of most disciplines. The control that we strive for has a strong impact on how we design our things and surroundings and has been destructive for the environment. This represents a paradox because our need for control has made our future less predictable. Rewilding is now one important method in restoring and healing nature, as well as striving to stop and restore climate change. The design epistemology represents a system that is reluctant to change; therefore, these forms of education do not provide designers with the methods needed to handle the uncertainty that produces such destructive changes. We see examples of trying to reconnect with nature that are romantic and fictional. The story of convenience, safety, and comfort [4] hides the story of decreased flexibility and manifold [5]. Our systems of industrial growth represent a paradigm that lacks consideration of the limited natural resources and intrinsic value of species other than the humans that destroy their own basis of life. Therefore, we need a change in epistemology or paradigm that can lead to a new awareness. A paradigm change is regarded by Meadows as the second most influential leverage point for transforming or changing systems [3]. Such a shift in paradigm can be exemplified by an awareness about the uncertainty that caused the destruction and exploitation of nature. Such a major shift will influence create a major turn in humans' conception of their own place and role in the world, as well as understanding of the systems of Gaia. In this context, Macy mentions this change of awareness as the "Great Turning" [4].

\section{CHANGE OF DESIGN PERSPECTIVE THROUGH SYSTEMS THEORY}

Krippendorff [6] points toward the importance of a turn in designers' approaches in design, from the traditional proposal of drawings, models, and written words to a participatory approach designing together with a range of stakeholders, leaving behind "THE user" as a simplified factor. He states that "human centered design creates possibilities of others." This view aligns with the functioning of flexibility and resilience. Designing flexibly for people and nature advocates a low entropy [7], which strengthens the sustainability of the system; it calls for simplicity, a few simple principles creating robustness that serve the options for complexity [3]. The design will serve a diversity of people, time span, and change in context. The increase in the number of choices for solutions brings uncertainty of context as an inspiring element for creativity and mastering.

\subsection{Theory bringing uncertainty to the table of benefits}

Joanna Macy [4] presents the five gifts or rewards of uncertainty: 1) The present moment, or discover this living life, one where the individual does not have to check their hope - this takes one out of the present moment; 2) the power of intention; 3) become whole by befriending pain; 4) solidarity with all relations; and 5) time, the immensity of time. Macy's dimensions emerged from cybernetics and are typically oriented toward the study of the now and a praxis that can be understood as behavior and thinking [8]. Based on this, we can discuss how the managing of a design project would function differently if there existed an individual and common toolbox for understanding, monitoring, and evolving, along with adapting the phases of the design process. This would come in addition to the ability to communicate the gained insight, dialogues, and decision making, facilitating the progress of a development process.

\subsection{From perfectionism to plasticity}

The search for the perfection of a malfunctioning system is a dead end when the system is about to go through a transition of change; when there are relationships between elements as part of a structure, it is of crucial to create change. The solution is a continuous movement from one state to a new desired level, rather than a new permanent and perfected state. Perfection is most often not possible when people, animals, nature, or living systems are involved. Hence, design is moving from a more static goal to a service or experience in an overarching system or a physical product that may be repaired, reused, remanufactured, recycled, or just being used in different ways, here depending on context and relations. This calls for solutions with simple and robust structures. We may need to move from complicated 
specializations to archetypes and the basic principles of solutions that can be understood and interpreted in many ways.

\subsection{System dynamics from numbers and computer simulations to qualitative design tools}

Meadows [2,9] explains how researchers in system dynamics have been surprised by the findings of how mathematical models are important to demonstrate how systems actually work. However, as designers, we usually do not have the skills or ambitions to compute and simulate feedback loops and relations. In systems theory, we may reach for the qualitative descriptions of phenomena made by scientists such as Meadows and Bateson. "Modern systems theory, bound up with computers and equations, hides the fact that it traffics in truth known at some level in everyone. It is often possible, therefore, to make translation from systems jargon to traditional wisdom." Meadows p3 [9]. We introduce for the students the description of leverage points, as well as the traps and opportunities of troublesome systems, and the lessons, or lenses for recognizing the behavior and dynamics in systems.

\section{The eight traps of troublesome systems}

Even though the design approach mentioned here is not pinpointing a problem at first, there are certain characteristics to recognize in unsustainable systems. Systems will break down at some point. We will not go deeply into this area, but we will mention three behavior archetypes that represent troublesome structures: addiction, drift-to-flow performance, and escalation. When evaluating the sustainability performance of a system, it is important to detect the roots of these behaviors.

\section{The fifteen lenses of transition}

How do we design with numerous stakeholders? Donella Meadows invites us into the entanglement of stakeholders and uncertainty with her lenses of transition. As we gain deeper insights into the systems, they end up as energies and relations that we would never be able to intuitively predict. She describes fifteen lessons, or lenses, that are key encountering systems; these are brought into design teaching and proposed as important when stepping into the uncertainty of complexity. Building on the above theoretical framework, we have synthesized the below method for designers that supports a process of modeling possible futures and perhaps coping with how to work with the uncertain.

\section{FROM SYSTEM THEORY TO PRACTICE, EXPECTING THE UNEXPECTED}

\subsection{A draft-framework monitoring uncertainty in systems design}

For a future designer to handle such processes, we have developed a rough framework (Table 1) for leading and monitoring a flexible design process based on experiences from systemic design, cybernetics, and system theory [2]. The framework is based on a net of system lenses and guidelines based on her grounded theory, and the framework builds on three phases: the twelve leverage points, the fifteen lenses of transition and living in systems, and the eight traps from the three archetypes of troublesome systems. The framework consists of three main stepping stones. These stepping stones have emerged as a draft, based on experiences from interdisciplinary students teams as well as design practice:

The Exploration "What is?" Stepping stone 1 relates to Joanna Macy's first gift of uncertainty: the importance of the present moment. The process and leadership of a transition starts entering a messy system, detecting the relations, structures, elements, and behavior of stakeholders in the system, as well as the system itself. Accepting painful parts, challenges, and destruction is important to discover how the system may be structured in ways that are troublesome. Evaluating feedback loops, for example, may help in detecting the root causes for dysfunctional behavior.

The journey "Where can we go?" Stepping stone 2 relates to the empathy with all living things, or "solidarity with all our relations" with the planet as such, as well as with the diversity of people, species, and the intrinsic value of these. Time is an important dimension. There is very often a call for quick action, whereas this stepping stone should be explored over time and allow for some reflection. Traditionally, this is a phase where design strategies are discussed, as well as the strategic use of design comes into play. This stepping stone is powered by leverage points theory from systems theory 
that utilizes discussions about where to intervene in a system and how.

The challenge of transition "The turning point." Stepping stone 3 relates to the power of intention. Early exploration of a minimum viable product (MVP) and early testing of interventions are done at a minimum scale and costs. Real people, context, and experiences are part of the development. Systems are always coupling and uncoupling the large and small, the fast and slow. Testing and evaluating consists of practice and theory, and the results are carried further into foresight and future scenarios. The method helps us see what is important to keep and simplify and the actions needed to start today for upscaling, such as a business model with different levels of complexity, from the fine details to the distribution system.

\section{Table 1. The systemic framework for design in uncertainty}

\begin{tabular}{|c|c|}
\hline Stepping stones & Dominating approaches \\
\hline $\begin{array}{l}\text { Stepping Stone } 1 \\
\text { The exploration of } \\
\text { "What is?" }\end{array}$ & $\begin{array}{l}\text { The eight traps of troublesome systems, and their behavior archetypes } \\
\text { - The discovering of addiction, escalation or drift to low performance, show traps for opportunities for } \\
\text { change. Some are; the tragedy of the commons, policy resistance, success to the successful. } \\
\text { Some lenses of transition } \\
\text { - Get the beat of the system. "Before you disturb a system in any way, watch how it behaves." Focus on } \\
\text { facts, not theories. Timeline, observations, and data. } \\
\text { - Locate responsibility in the system that generates action and feedback loops reflecting the } \\
\text { consequences to those responsible. }\end{array}$ \\
\hline $\begin{array}{l}\text { Stepping Stone } 2 \\
\text { The journey } \\
\text { "Where can we } \\
\text { go?" }\end{array}$ & $\begin{array}{l}\text { Some lenses of transition } \\
\text { - Expose your mental models to the light of day-words, pictures, arrows.... Find uncertainties and } \\
\text { mistakes—invite others to challenge your assumptions. Defy the disciplines. } \\
\text { Listen to the wisdom of the system ... don't destroy the system's own self-maintenance capacities. } \\
\text { Talking to people, observing, and searching for values to bring further. How can these be } \\
\text { strengthened through system development/interventions? } \\
\text { - Pay attention to what is important, not just what is quantifiable, e.g., trust among people in a } \\
\text { system—or to the system. Care, freedom, democracy, truth, love, and meaning. Social sustainability. } \\
\text { - Expand the time horizon, } 1000 \text { years back and forth ... the forest — the building. } \\
\text { - Celebrate complexity. Systems are nonlinear ... But a few simple principles make complexity. } \\
\text { The twelve leverage points } \\
\text { The most leverage lays in change of values of paradigm or goal and purpose of the system, changing } \\
\text { - the mind-set out of which the system arises } \\
\text {-the purpose of the "game", ex from competition to cooperation. } \\
\text { Leverage points for information flow and control are important, and typical here to intervene is by } \\
\text { - adding new rules, feedback loops, or structures that breed continuity, regeneration and then self- } \\
\text { organizing structure. } \\
\text { redesigning the relations in a system. "Win-win" solutions that create interconnection- stakeholders } \\
\text { might have different purposes in the system, but they support an overarching goal. } \\
\text { balancing feedback-loops } \\
\text { Physical structures are crucial, but are rarely leverage points. They should be designed well in the first place and } \\
\text { used within their potentials and constrains. }\end{array}$ \\
\hline $\begin{array}{l}\text { Stepping Stone } 3 \\
\text { The challenge of } \\
\text { transition "the } \\
\text { turning point" }\end{array}$ & $\begin{array}{l}\text { The fifteen lenses of transition } \\
\text { - Don't erode the goodness. Never leave the goals of the "standard" or compromise on what you know } \\
\text { is important in your system. } \\
\text { - Systems are always coupling and uncoupling the large and small, the fast and slow. } \\
\text { Testing and evaluating consists of practice and theory—-the results are carried further into foresight } \\
\text { and future scenarios. The method helps us see what is important to keep and simplify and the actions } \\
\text { that are needed to start today for upscaling (e.g., business model with different levels of complexity- } \\
\text { from detail to distribution system). } \\
\text { Use language with care, and enrich it with systems concepts. We see what we talk about- try to } \\
\text { express the concrete and meaningful important principles of the system. } \\
\text { Honor, respect, and distribute information. Information holds systems together-wrong, delayed, or } \\
\text { missing information can make feedback loops malfunction - this can drive a system crazy. } \\
\text { Go for the good of the whole. Don't maximize subsystems; aim for total system properties growth } \\
\text { (regenerative types), diversity, stability, resilience, and sustainability. } \\
\text { - Stay humble-stay a learner. What happened with your systems meeting COVID-19? Error- } \\
\text { embracing is the condition of learning. } \\
\text { Make feedback policies for feedback systems. Feedback structures for learning and monitoring the } \\
\text { system. }\end{array}$ \\
\hline
\end{tabular}




\section{CASES FROM DESIGN TEACHING}

\subsection{Intersystem analysis, an introduction to uncertainty, stepping stone 1}

Students are usually trained in searching for a problem, researching the people affected by it, the situation causing it, and then continuing with criteria for new idea generation for solutions and so on. In many institutions, the design thinking methodology has replaced the more engineering detailed approach; however, convergent and divergent thinking and working methods are characteristic for a designer's approach. This approach works well with rather domestic problems. When working with "wicked problems" [10], however, this methodology is not suitable. The problem we see is usually just a consequence of systemic errors on deeper levels.

To introduce this thinking to master's students in product design, we have proposed an intersystem analysis that is presented as an open approach to analyze an activity or experience. The students would then need to study the sectors and stakeholders interacting that make the foundation for the activity to happen. We further motivate the students to visualize a synthesis map, and based on this, we can explore the context in a frame that is as wide as possible. Furthermore, the heart or intension of the system is described, which may convey the most interesting activities happening in the system. The map is then mirrored with the eight principles of sustainability to describe where and how the sectors misalign with the principles. This first stepping stone- - What is?"-leaves the student with a range of challenges that can be explored further and evaluated as tasks that are suitable for a designer's toolkit for further development and change or even deeper system transition.

\subsection{Game dynamics in design, feedback loops for change, stepping stone 2}

Play and playfulness concerns exploration, risk taking, search for new sensations, engagement, and testing out ideas, here consisting mainly of communication by messaging between people or people and phenomenon. Thus, play involves seeking change and designing or framing [11] for play. This involves the design of allopoietic systems, that is, systems that produce something other than themselves [12]. A game design can then be oriented about the designing of reactions, quarrels, social interactions, deceiving, teaming up for a victory, and tuning of techniques, all of which can be understood as various descriptions of feedback loops caused by the thing, not the thing itself. Thus, the play activity is invented and sustained by feedback loops, and the oscillating variations of these loops are strengthened or balanced by the rules. This second step stone introduces the possibility of experimentation with the effects of feedback loops because the designing of a game itself demands thinking about the dynamics caused by communication sequences. These can be understood as drives, and in play theory, "the purpose of a drive is not to reach its goal (a final destination) but to circle around it, which brings about achievement of its aim" [Lacan in; 13], and that aim is about a mission. To exemplify this, Lacan explains that "when you entrust someone with a mission, the aim is not what he brings back, but the itinerary [journey] he must take...the aim is the way taken" [in; 13]. That is, experimenting with game dynamics in design is a process that involves experimenting with the question of "where can we go?" thus broadening the understanding of designing praxes and behavior by play elicited by such journeys.

\subsection{Experiencing the real thing (working in the fields), a taste of stepping stone 3}

"We see what we talk about"-it is usually difficult in a pedagogical context to bring in real testing with the right stakeholders and in a proper time span. Testing design concepts for system change most often requires a certain number of frequencies and maturing to see the evolvement and effect of the activities performed. A delay is always present to some degree. An activity may be experienced as fun and exciting for the first three days but after that may become tiresome, so the partakers will go back to their old routines. At the master's level, the three levels of learning by Bateson were introduced through a working day at a community supported farm [8]. The students worked with physical labor for half a day, performing practical tasks. Their contact with the soil, plants, and pigs and smelling the area made the experience real, giving them a surprising notion of joy. The work was explained and thought of as a basic activity with a clear goal (level 1). The students were verbally introduced to the circular thinking and interconnection between the plants, the soil, animals, and people. Choices of plants and animals may change in great variety; however, there are principles of interconnections that must be followed as important values. Then, there is the service system of the participants from the surrounding community 
working weekly on the farm and harvesting vegetables from the spring to late fall. Finally, the farm is being transformed from conventional food production to an organic farm, relating to the local and global ecology to a regenerative system in relation to nature. The metalevel of learning is brought into the conversation with the farmers. Questions emerge about the farmers' choice of lifestyle, their background, and path into this new way of living and establishing their local-based value chains. The third stepping stone is the beginning of transition in real life, and for these challenges, the interventions and new designs for change must usually be cared for and nurtured as long as they are in their original state. The goal of the intervention is often a self-organized system that will overtake the role of care and develop in an autopoietic way.

\section{REFLECTION AND DISCUSSION}

The intention of the current research was to supplement design thinking in design educations with an understanding of designed products and services as interfaces that can produce meaning above the "meaninglessness of physical properties" [14] and an orientation toward understanding design as communication or interfaces [14], thus moving away from THE user toward the notion of stakeholder networks, which can lead to processes that open up for understanding design as effects produced by something or someone that are shaped by systems dynamics. All of these may stimulate experimentation and coping with uncertainty in design. An introduction of the epistemological view of cybernetics and Bateson, which is oriented about the relations and communications and what it produces rather than an emphasis on the thing as a facet of designing in uncertainty, may open up for new design perspectives. If the student is released from an understanding of the influence of THE product and begins to explore the influence of communication systems formed by interaction and feedback loops, this may, for example, orient the design process away from the goal of controlling people's progression in a service to creating concepts of emergence. The concept of working with uncertainty may involve giving power to the interaction that happens through the interface (product or service) to the elicited communication that the interface produces.

The pedagogical toolbox may become much richer in this field, and the use of play in systems thinking and learning is valuable. It gives the students the opportunity to actually experience uncertainty, as well as the very exciting relations discovered in the different types of structures and feedback loops. The experience of discovering errors and delays that cause an unexpected mess in the "corner" of a system might be stronger and more direct when it is experienced with one's own senses.

\section{REFERENCES}

1. Krippendorff K. My Scholarly Life in Cybernetics, 2019 (Philadelphia, PA).

2. Meadows D. Leverage Points: Places to Intervene in a System, 1999 (Hartland, VT).

3. Ashby WR. An Introduction to Cybernetics, 1963.

4. Macy J. and Brown MY. Coming Back to Life: The Guide to the Work that Reconnects, 2014 (New Society Publishers).

5. Eriksen T. Mind the gap: flexibility, epistemology and the rhetoric of new work. Cybernetics \& Human Knowing, 2005, 12(1-2), 50-60.

6. Krippendorff K. The cybernetics of design and the design of cybernetics. Kybernetes, 2007, 36(9/10), 1381-92.

7. Rovelli C. L'ordine del Tempo, 2017 (Adelphi).

8. Bateson G. Steps to an Ecology of Mind, 2000/1972 (University of Chicago Press, Chicago).

9. Meadows D.H. and Wright D. Thinking in Systems: A Primer, 2009 (Earthscan, London).

10. Rittel H. and Webber M. Dilemmas in a general theory of planning. Integrating Knowledge and Practice to Advance Human Dignity, 1973, 4(2), 155-69.

11. Goffman E. Frame Analysis: An Essay on the Organization of Experience, 1986 (Northeastern University Press, Boston).

12. Mancilla R.G. Introduction to sociocybernetics (part 1): third order cybernetics and a basic framework for society. Journal of Sociocybernetics, 2013, 9(1/2).

13. Kreft L. Aesthetic imagination in football. Sport, Ethics and Philosophy, 2015, 9(2), 124-39.

14. Krippendorff K. An epistemological foundation for communication. Journal of

Communication (pre-1986), 1984, 34(3), 21. 